\title{
The Short-Term Patency Rate of a Saphenous Vein Bridge Using the No-Touch Technique in off-Pump Coronary Artery Bypass Grafting in Vein Harvesting
}

Teng-Yue Zhao*

Ji-Qiang Bu*

Jian-Jun $\mathrm{Gu}$

Yu Liu

Wen-Li Zhang

Zi-Ying Chen

Department of Cardiac Surgery, The Second Hospital of Hebei Medical University, Shijiazhuang, 050000, People's Republic of China

*These authors contributed equally to this work
Correspondence: Zi-Ying Chen Department of Cardiac Surgery, The Second Hospital of Hebei Medical

University, Shijiazhuang, 050000, People's

Republic of China

Tel +8615803210520

Fax +8631116188269

Email chenzy_de@I63.com
Objective: This study aimed to examine the short-term effect of the no-touch technique on the patency rate of a great saphenous vein (GSV) bridge used during off-pump coronary artery bypass grafting (OPCABG).

Methods: Between June 2018 and September 2020, 140 patients undergoing OPCABG, with grafts obtained from the GSV using the "no-touch" technique or the left internal mammary artery (LIMA), were enrolled in this study. The early clinical results and shortterm patency rate of the OPCABG were evaluated at a three-month follow-up by comparing the patency rate of the LIMA bridge and the GSV bridge obtained by the no-touch technique. This study also analyzed the impacts of the postoperative complications of the lower limbs and the distribution area of diseased vessels on the patency rate of a GSV bridge obtained by the no-touch technique at an early stage.

Results: No perioperative death or adverse cardiovascular or cerebrovascular events occurred in the 140 patients undergoing OPCABG. The difference in the early patency rate between the GSV bridge obtained by the no-touch technique and the LIMA bridge was not statistically significant $(95.9 \%$ vs $97.1 \%, p=0.501)$. There was no significant difference in the patency rate between an end-to-side anastomosed venous bridge and a LIMA bridge $(95.0 \%$ [248/261] vs 97.1\% [136/140], $\mathrm{p}=0.314)$. The overall patency rate of a no-touch vein bridge in the right coronary artery region was lower than it was in the left coronary artery region $(93.8 \%$ [165/176] vs $97.9 \%$ [183/187], $\mathrm{p}=0.049)$.

Conclusion: The no-touch technique may improve the early patency rate of a GSV bridge, and its effect is similar to that of a LIMA bridge.

Keywords: off-pump coronary artery bypass grafting, no-touch technique, great saphenous vein, left internal mammary artery

\section{Introduction}

Coronary artery bypass grafting $(\mathrm{CABG})$ is one of the most common operations in cardiac surgery, with the success of the operation depending on the long-term patency of the arterial or venous grafts. The current guidelines suggest that the left internal mammary artery (LIMA) should be the first choice for bridge vessels, while the great saphenous vein (GSV) is another option for CABG due to its superficial anatomical position, easy access, and low risk. As the most commonly used vascular material, grafts from the GSV account for more than $70 \%$ of all grafts. However, stenosis or occlusion often occurs in a GSV 
bridge obtained using the conventional technique. Fitzgibbon et $\mathrm{al}^{1}$ reported that the patency rate was $81 \%$ after one year, $75 \%$ after five years, and less than $50 \%$ after 15 years. Goldman et $\mathrm{al}^{2}$ reported that the 10 -year patency rate of LIMA bridge was $85 \%$, while that of the venous bridge was only $61 \%$. Therefore, the patency rate of GSV bridges is a focus of study in the field of coronary surgery. At present, it is thought that using an inappropriate method of venous acquirement may be one of the important factors affecting the long-term patency rate of venous bridges. In 1996, Souza $^{3}$ first proposed that using the no-touch technique could improve the patency rate of GSV bridges, and Samano et $\mathrm{al}^{4}$ reported that the 16-year patency rate of a GSV bridge obtained by the no-touch technique after CABG was almost equal to the patency rate of LIMA bridges. This technique has been reported in Europe and America, but it is rarely used in Asia, especially in off-pump CABG. Between June 2018 and October 2019, we obtained GSV grafts for 140 patients with coronary heart disease using the no-touch technique, and offpump coronary artery bypass grafting (OPCABG) alone was performed. Grafts from the LIMA artery were used as a control to evaluate the short-term patency of the no-touch technique in OPCABG.

\section{Materials and Methods}

This single-center randomized trial was conducted in consecutive patients undergoing elective first-time OPCABG and no other procedure in the Department of Cardiovascular Surgery at the Second Hospital of Hebei Medical University. The study was conducted in accordance with the Declaration of Helsinki (as was revised in 2013). The study was approved by the Ethics Committee of the Second Hospital of Hebei Medical University. All patients were informed about the purpose of the study and written consent was obtained from each patient.

\section{Study Design}

Exclusion criteria included patients with the following: a left ventricular ejection fraction $<50 \%$, chronic renal failure, emergency surgery, a preoperative intra-aortic balloon counterpulsation implantation, an expected survival time due to malignant tumor $<1$ year, a slender GSV (diameter $<1.2 \mathrm{~mm}$ indicated by vascular ultrasound), bilateral varicose GSVs or a previous history of venous exfoliation, and an allergy to contrast media. Bypass grafting of the anterior descending branch was performed using the LIMA in each patient, and the GSV obtained using the no-touch technique was used as a graft for the other diseased vessels. The patency rate of the LIMA bridge was then compared with that of the GSV bridge in these subjects. Power analysis showed that the sample size was adequate.

\section{Patient Characteristics}

Between June 2018 and September 2020, 140 consecutive patients underwent OPCABG with the use of the no-touch GSV harvesting technique. Aspirin and clopidogrel were administered at doses of $100 \mathrm{mg} /$ day and $75 \mathrm{mg} /$ day from the second day after the operation. If the patient's blood level of low-density lipoprotein cholesterol was high (more than $100 \mathrm{mg} / \mathrm{dl}$ ), drug treatment was started. Preoperative data were obtained from each patient's medical history and preoperative examination, including age, gender, body mass index (BMI), smoking history, hypertension history, stroke history, diabetes history, dyslipidemia, preoperative percutaneous coronary intervention history, chronic obstructive pulmonary disease history, vascular type, and LIMA and GSV diameters (Table 1). The data collected included the anastomosis mode of the target vessels and the number of unobstructed bridge vessels (Table 2).

Table I Preoperative Characteristics and Risk Factors of Study Patients

\begin{tabular}{|l|l|}
\hline Variables & All Study Patients(n= I40) \\
\hline Age (years) & $60.9 \pm 7.3$ \\
\hline Female (cases) & $29(20.4 \%)$ \\
\hline Risk factors & \\
Smoking (cases) & $59(42.1 \%)$ \\
Body mass index (Kg/m2) & $26.1 \pm 2.8$ \\
Hypertension (cases) & $93(66.4 \%)$ \\
Diabetes mellitus (cases) & $41(29.3 \%)$ \\
Dyslipidemia (cases) & $55(39.3 \%)$ \\
History of stroke (cases) & $20(14.3 \%)$ \\
Previous PCI (cases) & $8(5.7 \%)$ \\
Left main disease (cases) & $82(58.6 \%)$ \\
Three-vessel disease (cases) & $51(36.4 \%)$ \\
COPD (cases) & $1 \mathrm{I}(7.9 \%)$ \\
\hline Diameter of LIMA (n.) & $2.6 \pm 0.6$ P>0.05 \\
\hline Diameter of SVG (n.) & $2.5 \pm 0.5$ \\
\hline
\end{tabular}

Abbreviation: COPD, chronic obstructive pulmonary disease. 
Table 2 Number of Distal Anastomoses Between SVG and LIMA and Conduit Patency of Target Coronary Arteries

\begin{tabular}{|l|l|l|l|l|l|l|}
\hline $\begin{array}{l}\text { Target } \\
\text { Coronary } \\
\text { Arteries }\end{array}$ & Total & $\begin{array}{l}\text { Total Patency } \\
\text { Rate }\end{array}$ & $\begin{array}{l}\text { End-to-Side } \\
\text { Anastomosis }\end{array}$ & $\begin{array}{l}\text { End-to-Side } \\
\text { Anastomosis Patency } \\
\text { Rate }\end{array}$ & $\begin{array}{l}\text { Side-to-Side } \\
\text { Anastomosis }\end{array}$ & $\begin{array}{l}\text { Side-to-Side } \\
\text { Anastomosis Patency } \\
\text { Rate }\end{array}$ \\
\hline LAD & 140 & $136 / 140(97.1 \%)$ & 140 & $136 / 140(97.1 \%)$ & 0 & 0 \\
DIG & 93 & $92 / 93(98.9 \%)$ & 15 & $100 \%$ & 78 & $77 / 78(98.7 \%)$ \\
RM & 2 & $100 \%$ & 2 & $100 \%$ & 0 & 0 \\
LCX & 4 & $100 \%$ & 4 & $100 \%$ & 0 & 0 \\
OBM & 88 & $85 / 88(97.0 \%)$ & 81 & $78 / 81(96.3 \%)$ & 7 & 0 \\
RCA & 3 & $100 \%$ & 3 & $100 \%$ & 0 & 0 \\
PLV & 66 & $61 / 66(92.4 \%)$ & 60 & $55 / 60(91.7 \%)$ & 6 & 0 \\
PDA & 107 & $101 / 107(94.4 \%)$ & 96 & $91 / 96(94.8 \%)$ & 11 & 102 \\
Total & 503 & $484 / 503(96.2 \%)$ & 401 & $384 / 401(95.8 \%)$ & 102 & $100 / 102(90.9 \%)$ \\
Vein graft & 363 & $348 / 363(95.9 \%)$ & 261 & $248 / 261(95.0 \%)$ & 102 & $100 / 102(98.0 \%)$ \\
\hline
\end{tabular}

\section{Operative Strategies}

\section{The No-Touch GSV Acquisition Technique}

The course and branches of the GSV were marked by Doppler ultrasound before the operation. After anesthesia, tissue scissors were used to cut the skin sharply upward from the ankle along the marked line, retaining the venous adventitia and surrounding adipose tissue. The electrocoagulation index was adjusted to $20-30 \mathrm{~J}$, and the subcutaneous tissue was fully dissociated along both sides of the vein with the help of the scissors. The width between the cutting paths of both sides of the vein was about $0.5-0.8 \mathrm{~cm}$, and the small nutrient vessels around the vein were reserved as far as possible. To reduce the time of the GSV in vitro, the branches of the GSV were ligated and cut off until the planned length of the vein was freed. The distal end of the GSV graft obtained by the no-touch technique was connected with an independent perfusion tube (FLY, China; Stockert S3, Germany) through a flushing needle for injection without external resistance, and then autologous blood containing papaverine + heparin $(30 \mathrm{mg}$ of papaverine $+2500 \mathrm{U}$ of heparin sodium) was injected into the blood vessel to make the blood flow out. In this way, the graft blood vessel was checked for patency and thrombosis. The measured pressure was about $25-35 \mathrm{mmHg}$.

In order to reduce the possibility of a mismatch with the primary coronary artery or LIMA and lower extremity vascular complications, bilateral GSVs of the lower leg were selected instead of those from the whole leg. In order to reduce the side injury and to avoid nerve and muscle injury, it was necessary to avoid any rough sudden movement in the process of vascular material acquisition. The branches of the GSV were carefully examined before use to prevent postoperative bleeding due to untreated saphenous branches. The proximal end of the GSV was anastomosed to the distal end of the target vessel, while the other end was clamped with a noninvasive bulldog clamp. After the proximal anastomosis was completed, the distal end of the venous bridge was anastomosed with the aorta. After hemostasis, a two-layer continuous suture was performed; continuous subcutaneous tissue was sutured with VICRYL (polyglactin 910) Suture 2-0, and the intradermal tissues were sutured with 3-0 thread. A compression bandage was applied using an elastic bandage for $48-72$ hours. $^{5}$

\section{The OPCABG Procedure}

The chest was opened through a standard median incision of the sternum, and the LIMA was harvested. The patient was injected intravenously with $1 \mathrm{mg} / \mathrm{kg}$ of heparin. The target vessels of the coronary artery were fully exposed with pericardial traction and a coronary artery stabilizer. Meanwhile, an intracoronary shunt thrombus and carbon dioxide aerosol tube were used to clear the local visual field of the coronary artery anastomosis. During the operation, normal body temperature and stable circulation were maintained. The anastomotic stoma was cut in the bridge vessel and target vessel with the same size, and the target vessel and bridge vessel were opened after continuous suture with $7-0$ or $8-0$ polypropylene suture. First, the LIMA was used to reconstruct the left anterior descending coronary artery, and the GSV graft obtained by no-touch technique was then used to reconstruct the left circumflex coronary artery. Next, the right coronary artery area was reconstructed, and finally the distal end of the GSV was 
anastomosed with the aortic wall. The blood flow of the bridge was measured with a flow meter, and the vessel bridges with unsatisfactory blood flow were anastomosed again. After proximal and distal anastomosis, protamine was used to neutralize the heparin. The same group of doctors conducted the operation and acquired the vascular materials using the fixed method. Here, OPCABG was used to take out the GSV using the no-touch technique, so the proximal end of the GSV was anastomosed to the distal end of the target vessel, while the other end was clamped with a noninvasive bulldog clamp. After the proximal anastomosis was fully completed, the distal end of the venous bridge was anastomosed with the aorta step by step. Once the GSV was removed, the distal end of the vein was connected to an independent perfusion tube attached to the cardiopulmonary bypass machine. Autologous blood, containing papaverine and heparin (30 mg $+2500 \mathrm{U}$ of heparin sodium), was smoothly injected into the vein, without resistance, to allow the liquid solution to just flow out and to check whether there was any branch bleeding. The required pressure was $25-35 \mathrm{mmHg}$, the value being related to the length and diameter of the graft. Whether the modified OPCABG can improve the medium- and long-term patency rate of venous bridges still needs research with larger sample sizes and longer-term follow-ups. The method of coronary artery transplantation, assisted by cardiopulmonary bypass, used by Professor Souza's team, in which the distal end of the vein graft was anastomosed to the aorta and the proximal end was temporarily connected to the arterial intubation, ${ }^{6}$ differs from the method used in our center. However, in the regions where OPCABG is widely used, it can provide experience and reference for the wider application of the no-touch technique in OPCABG. For now, although it is an extremely important step to use an independent cardiopulmonary bypass machine to provide appropriate and stable pressure, the operation is complicated. Thus, it is worth looking at simpler devices or operations that could replace it.

\section{Angiographic Evaluation of the Graft Patency}

Coronary angiography was performed three months after the operation with the patient's consent, regardless of any symptoms of angina pectoris. Coronary computed tomography angiography (CTA) was chosen because of its minimally invasive nature and reliability in identifying graft occlusion. ${ }^{7}$ Patients who had died, who refused angiographic evaluation, who were unable to complete coronary CTA, or who had impaired renal function were excluded from the angiographic follow-up. Coronary CTA was performed with a 128-slice spiral CT machine (Philips Brilliance ICT, Cleveland, USA). The heart rate of all subjects was controlled at 75 beats $/$ min. Breath hold training and heart rate measurement were carried out one hour before the examination. If the heart rate was $>75$ beats $/ \mathrm{min}$ and the patient had no contraindications, the patient had to take $10 \mathrm{mg}$ of metoprolol orally. The whole heart was scanned, the data were processed for surface reconstruction and spherical display, and the results were recorded and analyzed. In all subjects, coronary CTA was performed by manual injection of $1 \mathrm{mg} / \mathrm{kg}$ iodixanol. All the images were assessed through visual evaluation by two imaging experts from our center. No stenosis indicated fully unobstructed, stenosis $<50 \%$ was mild stenosis, stenosis of $50-75 \%$ was moderate stenosis, and stenosis $>75 \%$ was considered to be severe.

\section{The Evaluation of Clinical Outcomes}

Surgical all-cause mortality was defined as death from any cause within 30 days, including death after discharge, and any death that occurred during the hospitalization when the surgery was performed. When the value of creatinine kinase myocardial band isoenzyme (CK-MB) within 24 hours of the operation was more than five times the normal upper limit, with or without chest pain, chest tightness or other symptoms, it was regarded as myocardial infarction within 24 hours of an operation. The diagnostic criteria of myocardial infarction $>24$ hours after operation were as follows: ST segment elevation in electrocardiography (ECG) monitoring or ECG evolution progress, or new pathological Q wave with evolution in two or more continuous leads, new left bundle branch block, or a CK-MB value more than three times the normal upper limit. During the period of hospitalization in an intensive care unit and general ward, the patients were continuously monitored by postoperative ECG until the thoracic drainage tube was removed. Any short atrial fibrillation attack lasting more than 30 seconds during the operation was considered as the occurrence of atrial fibrillation. Respiratory complications included postoperative pneumonia or the need for long-term ventilator support for more than 48 hours. Stroke was defined as a new onset of neurological deficit lasting more than 24 hours without significant nonvascular causes. Postoperative lower limb complications included 
subcrustal healing and infection or wound dehiscence. Subcrustal healing occurs when, more than two weeks after an operation, the incision epidermis becomes necrotic, and there is a wide black brown hard callus. Infection or wound dehiscence means that the epidermis or subcutaneous tissue of the incision is not connected more than two weeks after the operation, thus needing additional repair or a secondary operation.

Three months after the operation, the patient was reexamined and underwent a coronary CTA. If the examination was not performed at the scheduled time, the investigators contacted the patient by telephone to confirm their condition. Clinical and angiographic follow-up was ended on February 30, 2020. The major cardiovascular and cerebrovascular adverse events included cardiac death, nonfatal acute myocardial infarction, coronary re-intervention (including re-CABG), and cerebrovascular accident.

\section{Statistical Analysis}

Data were analyzed and processed using statistical software SPSS 26.0. Normally distributed measurement data were expressed as mean \pm standard deviation $(\mathrm{x} \pm \mathrm{SD})$, and non-normally distributed measurement data were expressed as the median. Count data were expressed as frequencies and percentages and compared using a Chisquare test. A p $<0.05$ was considered statistically significant.

\section{Results}

\section{Clinical Outcomes}

No perioperative death or adverse cardiovascular or cerebrovascular events occurred. After operation, atrial fibrillation occurred in 15 patients $(10.7 \%)$, and respiratory complications occurred in three patients. Subcrustal healing occurred in 12 patients, and wound infection or dehiscence occurred in three patients, two of whom were rehospitalized for debridement, while another was hospitalized for debridement due to poor sternal healing. The results of the present study revealed no perioperative deaths or adverse cardiovascular or cerebrovascular events. Of the 15 vein grafts with occlusion, the target vessel was a diagonal branch in one patient $(1.1 \%)$, obtuse marginal branches in three patients $(3.0 \%)$, posterior branches of the left ventricle in five patients $(7.6 \%)$, and posterior descending arteries in six patients (5.6\%) (Figure 1).

\section{Three-Month Angiographic Results}

The three-month angiographic results showed no significant difference in patency rate between the GSV bridge obtained by no-touch technique and the LIMA bridge $(95.9 \%$ [348/363] vs $97.1 \%$ [136/140], $p=0.501)$. In this study, the patency rates of the end-to-side anastomosis venous bridge and the LIMA bridge were compared to rule out the interference of anastomotic methods with the patency rate. It was found that there was no difference between the two groups $(95.0 \%$ [248/261] vs $97.1 \%$ [136/ $140], \mathrm{p}=0.314)$. The target vessel anastomosis and patency rate of each bridge are presented in Table 2 .

The coronary CTAs showed that the vein grafts were either completely occluded or completely open, and there was neither local nor diffuse significant stenosis.

The total patency rate of a venous graft was $95.9 \%$ (348/363), and the patency rate of a LIMA graft was $97.1 \%(136 / 140)$, indicating that there was no significant difference in the patency rate between the two $(p=0.501)$. Therefore, it can be considered that there is no difference in the patency rate between venous bridges and arterial bridges.

According to our observations, the short-term occlusion rate of no-touch venous bridges is not related to age, gender, BMI, smoking, hypertension, diabetes mellitus, stroke history, or postoperative atrial fibrillation (Table 3).

\section{Discussion}

GSV is the most commonly used graft in CABG. However, research over a lengthy period of time demonstrated that the occlusion rate of a venous bridge after traditional GSV was higher than that of a LIMA bridge. ${ }^{2}$ The long-term patency rate of bridging vessels has always been the focus of clinical research, coronary surgeons having made many positive and rigorous attempts at finding suitable graft materials. The first was the exploration of the total artery bridge, including the bilateral internal mammary artery, right gastroepiploic artery, and radial artery, but due to various problems, such as the easy spasm of the artery bridge, the difficulty of obtaining it, the long learning curve, and the mindset of the surgeon, it has been difficult to achieve promotion of this method worldwide. ${ }^{8}$ Other directions have been the exploration of the venous bridge, the no-touch technique, the endoscopic technique, and the extra-bridge stent technique, ${ }^{9-11}$ which have all achieved positive short-term results. 


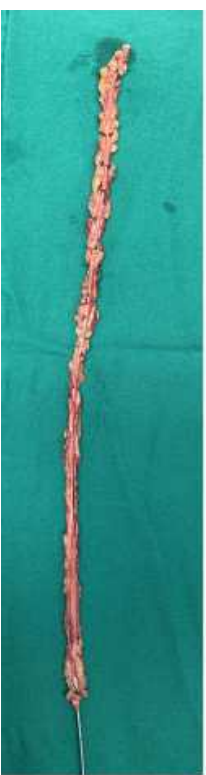

A

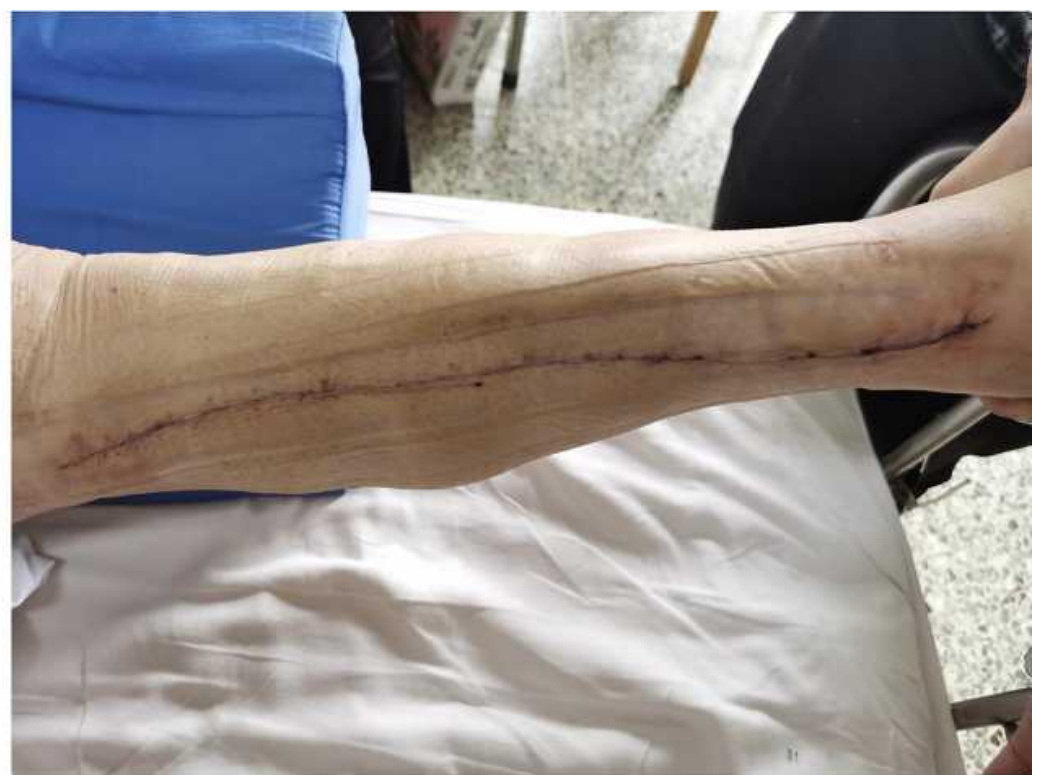

B

Figure I (A) The No-touch great saphenous vein obtained from patients. (B) One week after the great saphenous vein was obtained during surgery.

The quality of the GSV bridging vessel is the decisive factor in ensuring high patency. Usually, the mechanism of venous bridge restenosis and occlusion is mainly early acute thrombosis, mid-term intimal hyperplasia, and late atherosclerotic plaque formation. In the traditional method of obtaining GSV, mechanical injury and manual expansion in the process of vascular acquisition can damage the endothelium, and injury to the endothelium is one of the main reasons for platelet aggregation and thrombosis. The damage to the endothelium and the peeling of adventitia can reduce the level of nitric oxide (NO), resulting in vein spas. ${ }^{12}$ However, manual pressurized expansion to control the spasm can further damage the intima and media. ${ }^{13,14}$ Transient mechanical damage in the process of vascular acquisition and continuous damage in the arterial blood flow environment, after losing the protection of adventitia and perivascular tissue, can both lead to the activation, migration, and proliferation of vascular smooth muscle cells, resulting in neointimal hyperplasia of the vein. ${ }^{15,16}$ After stripping the adventitia, the vein loses its nutrient vascular network in the adventitia, resulting in ischemia in the veins. It is also one of the causes of intimal hyperplasia. ${ }^{17}$ In other words, the traditional way of harvesting the vein can cause damage to every layer of the vein structure.

Samano et $\mathrm{al}^{18}$ considered that the success of the notouch technique involved many factors. When a GSV graft is obtained using the no-touch technique, the vascular wall is not touched directly by any instrument, and the adventitia and surrounding tissues are preserved, preventing the occurrence of venous spasm, avoiding pressurized expansion against venous spasm, and protecting the integrity of the vein endothelium and middle smooth muscle layer to the maximum extent. This has been confirmed by electron

Table 3 Effect of Age and Other Factors on the Recent Occlusion Rate of Venous Bridges

\begin{tabular}{|l|c|c|c|c|}
\hline & Occlusion Group (n= I 7) & Patency Group (n= I 23) & Statistical Values & p-value \\
\hline Age (years) & $59.8 \pm 6.7$ & $61.0 \pm 7.4$ & -0.728 & 0.466 \\
Female (cases) & $3(17.6 \%)$ & $26(21.1 \%)$ & 0.000 & 0.989 \\
Body mass index $\left(\mathrm{Kg} / \mathrm{m}^{2}\right)$ & $26.7 \pm 2.6$ & $26.1 \pm 2.8$ & 0.863 & 0.390 \\
Smoking (cases) & $6(35.3 \%)$ & $53(43.1 \%)$ & 0.372 & 0.542 \\
Hypertension (cases) & $9(52.9 \%)$ & $84(68.3 \%)$ & 1.578 & 0.209 \\
Diabetes mellitus (cases) & $2(11.8 \%)$ & $39(31.7 \%)$ & 1.986 & 0.159 \\
History of stroke (cases) & $3(17.6 \%)$ & $17(13.8 \%)$ & 0.003 & 0.958 \\
Postoperative atrial fibrillation(cases) & $2(11.8 \%)$ & $13(10.6 \%)$ & 0.000 & 1.000 \\
\hline
\end{tabular}


microscopic observation. ${ }^{19}$ In addition, when a GSV graft with perivascular tissue is transplanted, paracrine signaling may affect a variety of cytokines, such as the adipose derived relaxing factor, NO, leptin, adiponectin, prostaglandin, hydrogen sulfide, and other vasodilators. ${ }^{19}$ A previous study revealed that the paracrine factors released by perivascular tissue can not only relax and contract blood vessels, but they also alter the structure of the blood vessel wall by changing cell migration, proliferation, and apoptosis. ${ }^{20}$ In addition, the intact perivascular vein tissue can be used as a natural external scaffold, which can reduce the risk of vascular angulation and distortion. $^{21}$

The results of the present study revealed no perioperative deaths or adverse cardiovascular or cerebrovascular events. This suggests that the shape of the distributions of the bridging vessels during the operation could be adjusted, and, if necessary, the perivascular tissue of the bridging vessels could be sutured and fixed with epicardium to prevent a change in the position of the bridge vessels after the operation, which may affect the prognosis.

One study found that minimally invasive arteriovenous composite grafts, anastomosed with the right coronary artery region with moderate stenosis $(<80 \%)$, often show competitive blood flow patterns in early postoperative angiography. ${ }^{22}$ In 1986, Watts et $\mathrm{al}^{23}$ found that the turbulence of blood flow in side-to-side anastomosis was less than that in end-to-side anastomosis. They believed that the difference in blood flow composition was the reason for the difference in the patency rate between side-to-side anastomosis and end-to-side anastomosis. These studies suggest that the factors in the traditional method of obtaining GSV that influence the patency rate of the venous bridge, such as the distribution of the target vessels and the type of anastomosis, may also exist in the no-touch technique.

However, the incidence of lower extremity incision complications is significantly higher than that of the traditional long incision method. ${ }^{5}$ The main manifestations are lower limb pain or numbness, edema or exudation, and an increased incidence of subcrustal healing under the scar. Major complications included subscab healing, while minor complications included lower limb pain or numbness, edema or exudation, and infection. The complications of lower limb incision can be lessened by reducing the use of an electrotome, avoiding excessive free perivascular tissue, obtaining the GSV of the bilateral lower leg instead of that of the thigh, replacing a compression bandage with an elastic bandage after the operation, and raising the affected $\operatorname{limb} .^{7}$ It is important to note that if there is no infection in the incision, no special treatment is needed, since the vast majority of the patients will heal spontaneously. However, when the incision is infected and necrotic, debridement and suture have to be performed promptly.

There are some limitations to the current research. First, this study was a single-center study, and although all consecutive patients meeting the inclusion criteria were included, too many exclusion criteria could still have exaggerated the observation effect, and there was also no control group. Second, the same patient population was used as the study cohort to compare the patency rates of an internal mammary artery bridge and a GSV bridge, and although the external factors of the coronary artery and bridging vessels were the same, it was difficult to avoid the impacts of the target vessel and bridge vessel themselves, and the number of bridging vessels was not considered. Finally, this study only analyzed the early clinical results and the 3-month patency rates of the bridging vessels, so long-term follow-up is needed to obtain long-term patency rates.

\section{Acknowledgments}

We are particularly grateful to all the people who have given us help on our article.

\section{Funding}

This study was funded by the Hebei Provincial Department of Finance Government Funding for Specialty Capacity Building and Specialty Leader Training:Clinical Study on Emergency Bypass and Longterm Patency of Bridge Vessels in Critical Coronary Artery Disease (No.361004). The funding body had no role in the design of the study and collection, analysis, and interpretation of data and in writing the manuscript.

\section{Disclosure}

The authors declare that they have no competing interests.

\section{References}

1. FitzGibbon GM, Burton JR, Leach AJ. Coronary bypass graft fate: angiographic grading of 1400 consecutive grafts early after operation and of 1132 after one year. Circulation. 1978;57(6):1070-1074. doi:10.1161/01.CIR.57.6.1070

2. Goldman S, Zadina K, Moritz T, et al. Long-term patency of saphenous vein and left internal mammary artery grafts after coronary artery bypass surgery: results from a Department of Veterans Affairs Cooperative Study. J Am Coll Cardiol. 2004;44(11):2149-2156. doi:10.1016/j.jacc.2004.08.064 
3. Souza DS, Christofferson RH, Bomfim V, Filbey D. "No-touch" technique using saphenous vein harvested with its surrounding tissue for coronary artery bypass grafting maintains an intact endothelium. Scand Cardiovasc J. 1999;33(6):323-329. doi:10.1080/14017439950141362

4. Samano N, Geijer H, Bodin L, et al. The no-touch saphenous vein graft in elderly coronary bypass patients with multiple comorbidities is a promising conduit to substitute the left internal thoracic artery. $J$ Thorac Cardiovasc Surg. 2017;154(2):457-466.e3. doi:10.1016/j. jtcvs.2017.03.048

5. Ishizawa A, Hamasaki A, Uchida T, Sadahiro M. A novel harvesting technique for a no-touch saphenous vein graft using the THUNDERBEAT device. Multimed Man Cardiothorac Surg. 2018;2018.

6. Souza DS, Johansson B, Bojö L, et al. Harvesting the saphenous vein with surrounding tissue for CABG provides long-term graft patency comparable to the left internal thoracic artery: results of a randomized longitudinal trial. J Thorac Cardiovasc Surg. 2006;132(2):373-378. doi:10.1016/j.jtcvs.2006.04.002

7. Hamon M, Geindreau D, Guittet L, Bauters C, Hamon M. Additional diagnostic value of new $\mathrm{CT}$ imaging techniques for the functional assessment of coronary artery disease: a meta-analysis. Eur Radiol. 2019;29(6):3044-3061. doi:10.1007/s00330-018-5919-8

8. Mohr FW, Rastan AJ, Serruys PW, et al. Complex coronary anatomy in coronary artery bypass graft surgery: impact of complex coronary anatomy in modern bypass surgery? Lessons learned from the SYNTAX trial after two years. $J$ Thorac Cardiovasc Surg. 2011;141(1):130-140. doi:10.1016/j.jtcvs.2010.07.094

9. Ran J, Liu Y, Li Y, et al. The effect of endoscopic vein harvesting in coronary artery bypass surgery. J Thorac Dis. 2020;12(5):1991-1998. doi: $10.21037 /$ jtd-20-250

10. Meirson T, Orion E, Avrahami I. Numerical analysis of venous external scaffolding technology for saphenous vein grafts. $J$ Biomech. 2015;48(10):2090-2095. doi:10.1016/j.jbiomech.2015.03.011

11. Webb CM, Orion E, Taggart DP, Channon KM, Di Mario C. OCT imaging of aorto-coronary vein graft pathology modified by external stenting: 1-year post-surgery. Eur Heart $J$ Cardiovasc Imaging. 2016;17(11):1290-1295. doi:10.1093/ehjci/jev310

12. Parang P, Arora R. Coronary vein graft disease: pathogenesis and prevention. Can J Cardiol. 2009;25(2):e57-e62. doi:10.1016/S0828282X(09)70486-6

13. Souza DS, Arbeus M, Botelho Pinheiro B, Filbey D. The no-touch technique of harvesting the saphenous vein for coronary artery bypass grafting surgery. Multimed Man Cardiothorac Surg. 2009;2009(731): mmcts.2008.003624. doi:10.1510/mmcts.2008.003624
14. Angelini GD, Passani SL, Breckenridge IM, Newby AC. Nature and pressure dependence of damage induced by distension of human saphenous vein coronary artery bypass grafts. Cardiovasc Res. 1987;21(12):902-907. doi:10.1093/cvr/21.12.902

15. Khaleel MS, Dorheim TA, Duryee MJ, et al. High-pressure distention of the saphenous vein during preparation results in increased markers of inflammation: a potential mechanism for graft failure. Ann Thorac Surg. 2012;93(2):552-558. doi:10.1016/j.athoracsur.2011.10.035

16. Nolte A, Secker S, Walker T, et al. Veins are no arteries: even moderate arterial pressure induces significant adhesion molecule expression of vein grafts in an ex vivo circulation model. J Cardiovasc Surg. 2011;52(2):251-259.

17. Dreifaldt M, Souza DS, Loesch A, et al. The "no-touch" harvesting technique for vein grafts in coronary artery bypass surgery preserves an intact vasa vasorum. J Thorac Cardiovasc Surg. 2011;141 (1):145-150. doi:10.1016/j.jtcvs.2010.02.005

18. Samano N, Souza D, Dashwood MR. Saphenous veins in coronary artery bypass grafting need external support [published online ahead of print, 2020 Dec 13]. Asian Cardiovasc Thorac Ann. 2020;218492320980936.

19. Fernández-Alfonso MS, Gil-Ortega M, Aranguez I, et al. Role of PVAT in coronary atherosclerosis and vein graft patency: friend or foe? $B r \quad J$ Pharmacol. 2017;174(20):3561-3572. doi:10.1111/ bph. 13734

20. Simonsen U, Boedtkjer E. New roles of factors from perivascular tissue in regulation of vascular tone. Acta Physiol. 2016;216 (2):159-162.

21. Inaba $Y$, Yamazaki $M$, Ohono $M$, et al. No-touch saphenous vein graft harvesting technique for coronary artery bypass grafting. Gen Thorac Cardiovasc Surg. 2020;68(3):248-253. doi:10.1007/s11748019-01186-4

22. Kim YH, Oh HC, Choi JW, Hwang HY, Kim KB. No-touch saphenous vein harvesting may improve further the patency of saphenous vein composite grafts: early outcomes and 1-year angiographic results. Ann Thorac Surg. 2017;103(5):1489-1497. doi:10.1016/j. athoracsur.2016.09.024

23. Watts KC, Marble AE, Sarwal SN, Kinley CE, Watton J, Mason MA. Simulation of coronary artery revascularization. J Biomech. 1986;19 (7):491-499. doi:10.1016/0021-9290(86)90122-3
International Journal of General Medicine

\section{Publish your work in this journal}

The International Journal of General Medicine is an international, peer-reviewed open-access journal that focuses on general and internal medicine, pathogenesis, epidemiology, diagnosis, monitoring and treatment protocols. The journal is characterized by the rapid reporting of reviews, original research and clinical studies across all disease areas. The manuscript management system is completely online and includes a very quick and fair peer-review system, which is all easy to use. Visit http://www.dovepress.com/ testimonials.php to read real quotes from published authors. 